\title{
RESEARCH AND SYSTEM REALIZATION OF FOOD SECURITY ASSESSMENT IN LIAONING PROVINCE BASED ON GREY MODEL
}

\author{
Bin $\mathrm{Xi}^{1}$, Yunhao Chen ${ }^{1,2, *}$, Hongchun Cai ${ }^{1}$, Yang Liu ${ }^{1}$ \\ ${ }^{1}$ College of Resources Science and Technology, Beijing Normal University, Beijing, China, \\ 100875 \\ ${ }^{2}$ Academy of Disaster Reduction and Emergency Management Ministry of Civil Affairs \& \\ Ministry of Education, Beijing Normal University, Beijing, China, 100875 \\ * Corresponding author, Address: College of Resources Science and Technology, Beijing \\ Normal University, No. 19 Xin Jie Kou Wai Street, Beijing, 100875, P. R. China, Tel: +86- \\ 10-58806098, Fax: +86-10-58806098, Email: Cyh@ires.cn
}

Abstract: Food security is a key component of state security, and every country, especially some great powers in the world, has been paying more attention to national food security and its security system. This paper aimed at applying grey model to food security assessment in the province scale from statistical data and developing a prototype of food security assessment system in Liaoning Province. Firstly, the use of grey models is a novel concept in food security assessment and the principles of $\operatorname{GM}(1,1)$ are explained systematically. Second, the framework of food security assessment is created based on three-tier architecture and the assessment system adopts the objectoriented development method and component technology. To show the validity and feasibility, the precision inspection is made under strict mathematical calculation. In the end, the realization of system results is presented partially. It is suggested that food security assessment based on grey model is an effective attempt to solve food security problems.

Keywords: food security assessment, grey model, three-tier architecture

Xi, B., Chen, Y., Cai, H. and Liu, Y., 2008, in IFIP International Federation for Information Processing, Volume 258; Computer and Computing Technologies in Agriculture, Vol. 1; Daoliang Li; (Boston: Springer), pp. 703-711. 


\section{INTRODUCTION}

Food security is a key component of state security, and every country, especially some great powers in the world, has been paying more attention to national food security and its security system. According to the food white book released by Chinese State Council in October 1996, the food demand in 2000 is 50 million ton (Wang et al., 2007). However, the annual food yield from 2000 is less than 46.5 million ton (Feng, 2007). The 2005 food yield increased to 48.4 million ton, but it didn't reach the predictive yield. There are some complicated relationship among food security, population and cultivated land. The average cultivated land area decreased to $40 \%$ of 1950' area on the account of the inverse trend between population and cultivated land. We can foresee that the decreasing trend of average cultivated land is difficult to reverse and food yield will be confronted with severe challenges during a long time.

The grey system theory is a multidisciplinary theory dealing with those systems for which we lack information (Deng, 2007). Because multiple factors in related to the assessment of food security will be influenced, such as population, cultivated land, food production, some are unknown, some are known, which have distinct dynamic characteristics and uncertainty, thus we belong them to grey system theory. Therefore, with the help of mathematical model resulted from grey system, we could do some research on food security dynamic change and trend so as to acquire the basis of food security system equilibrium.

Food security assessment consists of evaluating annual food total yield of Liaoning Province and its 14 prefecture level cities, market demands and food supply-demand assessment, etc. The following 4 elements, population, cultivated land area, food yield and structure, are the principal factors to measure land security. Besides them, food yield fluctuating coefficient, market supply coefficient, and cultivated land change coefficient should be paid some attention while doing comprehensive analysis.

\section{GREY PREDICTION MODEL}

\subsection{Grey Model Theory}

Grey system model or GM (m, n) is a modeling method based on the concept of grey model and take differential fitting method as core. the parameters $\mathrm{m}$ and $\mathrm{n}$ are the order of model differential equation and the 
sequences number of modeling, respectively. The more the order is, the more complex calculation and the less precision improved. Therefore, GM $(1,1)$ is adopted to be the prediction model (Mi et al., 2007). Considering an original time series is expressed as

$$
\left\{x^{(0)}(k)\right\} \quad(k=1,2, \Lambda, n)
$$

such a quantity was made an accumulating generation and it becomes

$$
x^{(l)}(k)=\left[x^{(l)}(1), x^{(I)}(2), \cdots, x^{(l)}(n)\right]
$$

where $x^{(I)}(k)$ is a progressive function relationship, which is modeling $\mathrm{GM}(1,1)$.

\subsection{GM $(1,1)$ Modeling and Its Solution Process}

According to the $\operatorname{GM}(1,1)$, the white differential equation is computed from equation (2).

$$
\frac{d x^{(I)}(k)}{d k}+a x^{(I)}(k)=u
$$

where $a$ is developing coefficient that controls system development. The factor $u$ is grey action to reflect the change of time series.

$$
x^{(1)}(k)=\sum_{i=1}^{t} x^{(0)}(i), \quad(k=1,2, \Lambda, n)
$$

In terms of least-square error method, the parameters in $\operatorname{GM}(1,1)$ are expressed as

$$
M=[a, u]^{T}=\left(B^{T} B\right)^{-1} B^{T} Y_{n}
$$

where

$$
\begin{gathered}
B=\left[\begin{array}{cc}
-0.5\left[x^{(I)}(2)+x^{(I)}(1)\right] & 1 \\
-0.5\left[x^{(I)}(3)+x^{(l)}(2)\right] & 1 \\
\vdots & \vdots \\
-0.5\left[x^{(I)}(n)+x^{(I)}(n-1)\right] & 1
\end{array}\right], \\
Y_{n}=\left[\begin{array}{c}
x^{(0)}(2) \\
x^{(0)}(3) \\
\vdots \\
x^{(o)}(n)
\end{array}\right] .
\end{gathered}
$$


Such a quantity $-0.5\left[x^{(l)}(2)+x^{(l)}(1)\right]$ could be defined to be nearest neighbor mean of $x^{(I)}(k)$. The factor $M$ is computed and the value of $a$ and $u$ are put into (3), then solving the differential equation where $x^{(1)}(1)=x^{(0)}(1)$ is the initial value and gives

$$
\hat{x}^{(I)}(k)=\left[x^{(I)}(1)-\frac{u}{a}\right] e^{-a k}+\frac{u}{a},(k=1,2, \Lambda, n)
$$

Using the predicted value given by (6) will have the predicted value $\hat{x}^{(0)}(k)$, when the time is at $k$.

$$
\hat{x}^{(0)}(k)=\hat{x}^{(1)}(k)-\hat{x}^{(1)}(k-1)
$$

\subsection{GM (1, 1) Precision Inspection}

The precision inspection should be made to determine whether the predicted value is believable or not. This paper adopts post-variance test method to do inspection. The variance proportion $c$ and small error probability $p$ in post-variance test method is expressed as

$$
c=S_{2} / S_{1}
$$

where $S_{2}$ and $S_{1}$ are mean square errors of residual and actual sequences, respectively.

$$
p=\left\{|\varepsilon(k)-\bar{\varepsilon}|<0.6745 S_{1}\right\}
$$

where $\varepsilon(k)$ and $\bar{\varepsilon}$ are the residuals sequence and its mean, respectively (Ye et al., 2005).

The less value the quantity $c$ is, the better prediction of GM model. The more the value $p$ demonstrates the more probability of little error and the higher precision. Table 1 is the value $c$ and $p$ under different precision levels.

Table 1. Standard of GM $(1,1)$ precision estimation

\begin{tabular}{lllll}
\hline Level of precision & Excellent & Good & Pass & No Pass \\
\hline$c$ & $<0.35$ & $0.35-0.50$ & $0.50-0.65$ & $>0.65$ \\
$p$ & $>0.95$ & $0.95-0.80$ & $0.80-0.70$ & $<0.70$ \\
\hline
\end{tabular}




\section{APPLICATION OF GM $(1,1)$ IN FOOD SECURITY PREDICTION}

\subsection{Introduction of Data Source}

According to the available information and the actual situation on Liaoning Province, the selected data consists of annual main corps yield, population, cultivated land area, food demand and main corps per area yield in Liaoning Province and its' 14 regional cities. All data comes from "Liaoning Statistical Yearbook" which was input into "food security.mdb" ACCESS database. The database includes the following data tables: cultivated land area and population of regional cities, food demand per capita, primary products yield per area in the prefecture level cities, and so on.

Table 2. Data Structure of Food Yield Data Table

\begin{tabular}{lll}
\hline Field name & Type & Description \\
\hline year & long & year \\
cur_sum & double & total food yield of this year $\left(10^{4} \mathrm{t}\right)$ \\
rice & double & total rice yield of this year $\left(10^{4} \mathrm{t}\right)$ \\
wheat & double & total wheat yield of this year $\left(10^{4} \mathrm{t}\right)$ \\
maize & double & total maize yield of this year $\left(10^{4} \mathrm{t}\right)$ \\
sorghum & double & total sorghum yield of this year $\left(10^{4} \mathrm{t}\right)$ \\
millet & double & total millet yield of this year $\left(10^{4} \mathrm{t}\right)$ \\
tubers & double & total tubers yield of this year $\left(10^{4} \mathrm{t}\right)$ \\
soybean & double & total soybean yield of this year $\left(10^{4} \mathrm{t}\right)$ \\
others & double & total others yield of this year $\left(10^{4} \mathrm{t}\right)$ \\
\hline
\end{tabular}

The above Table 2 is the data structure of food yield data table, one example of all the data tables.

\subsection{Food Security Assessment Flow Based on GM (1, 1)}

Food security assessment based on $\mathrm{GM}(1,1)$ is divided into three procedures:

(1) The description of problem. Given the formalized representation of problem to satisfy the demand of computer expressing and disposing, including the prediction of annual total food yield, market total demands prediction, yield-demands warning, and food integrated assessment warning in Liaoning Province and its' 14 prefecture level cities. Assessing result can be expressed in the patterns of curve, histogram and pie charts, and the food yield is forecasted grounded on diversified demand standard. 
(2) The division of problem. Four task presentations and self-precision inspection system of the food security assessment will be solved simply and obviously.

(3) The solution of problem. The brief and clear system interface and selfgenerated result files are good to the problem solving.

The framework of food security assessment system can be expressed as Figure 1.

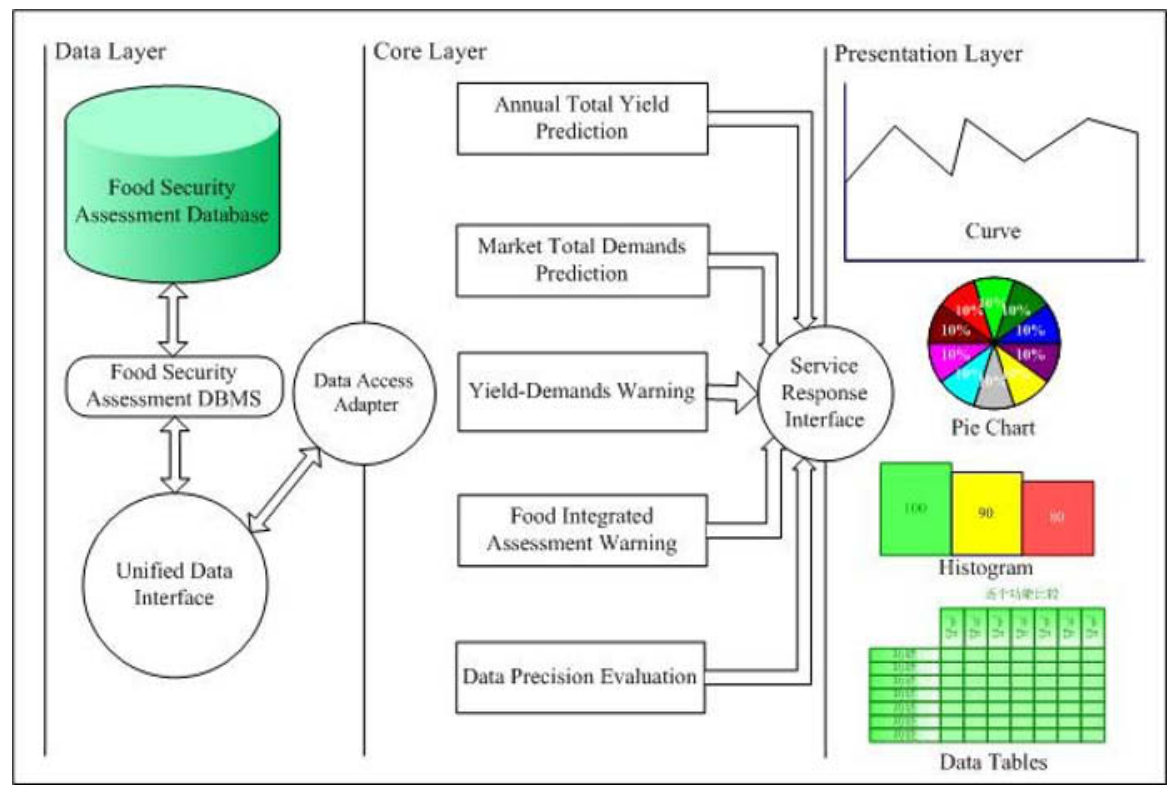

Figure 1. Food Security Assessment System Framework

There is a three-tier architecture used in the food security assessment system, which contains data layer, core layer and presentation layer and they are responsible for achieving data access, function processing and the display of assessment results, respectively (Cai et al., 2006).

(1) Data layer

Food security assessment system contains plenty of statistical data tables, and the function of data layer is to do some operations about reading, writing and deleting the statistical data from the assessment database. It is capable of reducing the dependence of core layer to concrete data and increasing the transparence of database access and system flexibility. Assessment system is managed by specialized DBMS, which supplies unified data interface and data access adaptor to transport information to core layer (Liu et al., 2006).

(2) Core layer

Core layer is the kernel of assessment system, which is responsible for the implementation of system tasks. It responds to the requests of data access 
adaptor, operations of database, transaction of system tasks, and then reflected on the presentation layer through service response interface.

(3) Presentation layer

Based on the three-tier architecture model, presentation layer is mainly responsible for the results of assessment display. Presentation will respond according to the reception from core layer, and show the assessment results in the form of curves, histogram, pie charts and tables. During the processing of requests responding and results generating, core layer will connect with data layer to store the assessment outcome if necessary.

\subsection{Precision Evaluation}

GM $(1,1)$ model is created based on the time series formed by the total food total yield data of Liaoning Province in year of 1980-2005. We define 3 as the system prediction interval to predict yield, so there are 8 values to compare with the 8 actual yields under the precision evaluation (Table 3 ).

Obviously, it has a high credibility from the comparison of the value $c$ and $p$ in Table 3 and the level of precision in Table 1. The following system running of food security integrated assessment is illustrated in Figure 3.

Table 3. Result of Precision Evaluation

\begin{tabular}{llccc}
\hline Year & Interval & Actual yield $\left(10^{4} \mathrm{t}\right)$ & Predicted $\left(10^{4} \mathrm{t}\right)$ & Relative error \\
\hline 1983 & 3 years & 1485.2 & 1314.3 & $11.51 \%$ \\
1986 & 3 years & 1222.2 & 1106.3 & $9.48 \%$ \\
1989 & 3 years & 968.2 & 802.3 & $17.14 \%$ \\
1992 & 3 years & 1588.6 & 1522.7 & $4.15 \%$ \\
1995 & 3 years & 1390.5 & 1246.6 & $10.35 \%$ \\
1998 & 3 years & 1960.0 & 1804.1 & $7.95 \%$ \\
2001 & 3 years & 1419.9 & 1254.0 & $11.68 \%$ \\
2004 & 3 years & 1955.7 & 1659.8 & $15.13 \%$ \\
$c$ & & \multicolumn{3}{c}{0.438} \\
$p$ & & 0.875 & \\
\hline
\end{tabular}

\subsection{The Realization of Food Security Assessment}

The food security assessment system is composed of 4 models, Annual Total Yield Prediction, Market Total Demands Prediction, Yield-Demands Warning and Food Integrated Assessment Warning. The two picture Fig. 2 and Fig. 3 display the models of Market Total Demands Prediction and Food Integrated Assessment Warning, respectively. 


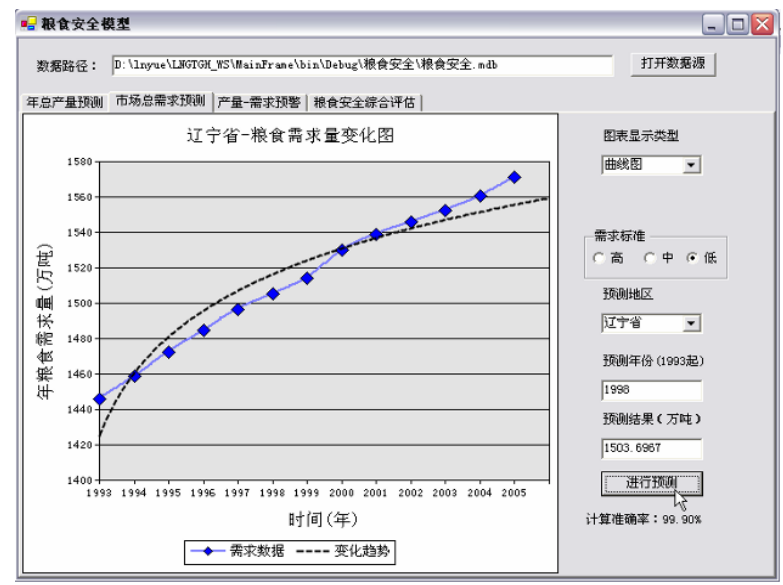

Figure 2. Market Total Demands Prediction

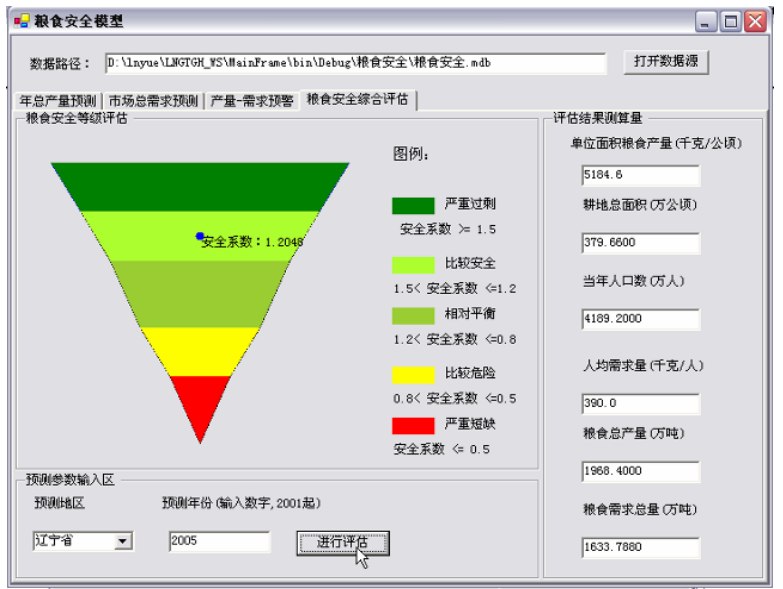

Figure 3. Food Integrated Assessment Warning

We can see from Figure 3 the safe coefficient of food security assessment of Liaoning Province in 2005 is 1.2048, which is in the light green region and indicates the security degree is relative safe.

\section{CONCLUSIONS}

Grey model, which is widely used in the field of science and technology, has a good performance.

The use of grey models is a novel concept in food security assessment, and it provides a new scientific method or insight for analytical prediction in food security field. In the paper, the result indicates high validity and feasibility of food security assessment based on GM $(1,1)$ model. 
Moreover, the framework of food security assessment is created based on three-tier architecture and the assessment system adopts the object-oriented development method and component technology.

At last, the realization of the assessment system presented successfully. It is suggested that food security assessment based on grey model is an effective attempt to solve food security problems.

\section{ACKNOWLEDGEMENTS}

This study has been funded by China National 863 Plans Projects (Contract Number: 2006AA120102).

\section{REFERENCES}

Cai Hongwei, et al. Research and appliance of the flexible three-tier architecture. Journal of Zhejing Sci-Tech University, 2006, 23(2): 178-181 (in Chinese).

Deng Julong. The Journal of Grey System. http://www.researchinformation.co.uk/grey.php, 2007.

Feng Zhiming. Future food security and arable land guarantee for population development in China. Population Research, 2007, 31(2): 15-29 (in Chinese).

Liu Hongtao, et al. Management system based on the B/S mode three-layer structure. Seismological Research of Northeast China, 2006, 22(1): 75-80 (in Chinese).

Mi Hongyan, et al. Application of the Grey Model GM $(1,1)$ to forecast of building settlement. Journal of Southwest Forestry College, 2007, 27(1): 81-84 (in Chinese).

Wang Wenlong, et al. China food security problem: not only the surface but also the bottom. Reformation and Strategy, 2007, 4: 39-41 (in Chinese).

Ye Mingquan, et al. Seasonal artificial neural network forecasting model and its application in the $\mathrm{GM}(1,1)$ residual error correction, Computer Engineering and applications, 2005, 41(1): 194-196 (in Chinese). 